\title{
Sleep Quality and Fatigue in Egyptian Rheumatoid Arthritis Patients
}

\author{
MERVAT ESSAM BEHIRY, M.D. \\ The Department of Internal Medicine, Faculty of Medicine, Cairo University
}

\begin{abstract}
Background: Pain, fatigue \& sleep disturbance have been linked to lower quality of life \& reduced survival among patients with Rheumatoid Arthritis (RA).

Aim of study: Assessment of sleep abnormality, pain and fatigue symptoms among RA patients and their relations with disease activity and other patient characteristic data.

Subjects and Methods: Eighty-four patients with RA fulfilling the 2010 American College of Rheumatology (ACR)/ European League Against Rheumatism classification criteria were enrolled in the study. Disease activity as evaluated by Disease Activity Score 28 (DAS28). Sleep quality was assessed by Pittsburgh Sleep Quality Index (PSQI), pain intensity was measured by Visual Analog Scale (VAS), while fatigue was assessed by Fatigue Severity Scale (FSS).

Results: The mean age of the participants was $45 \pm 8$ years, the mean Disease Activity score (DAS28) was $4.2 \pm 1.3$, the patients had poor sleep quality with the mean PSQI was $0.9 \pm$ 1.2 , the mean VAS score was $7 \pm 2.39$ and the mean FSS was $5.13 \pm 1.75$. Strong correlations were found between the DAS28 score and each of PSQI, FSS, and VAS ( $r$-value $0.75,0.85 \&$ 0.74 respectively) with $p$-value $(0.02,0.001$ and 0.03 respectively).

Conclusion: Sleep disturbances and fatigue were commonly noticed in RA patients due to interaction of pain and disease activity.
\end{abstract}

Key Words: Rheumatoid arthritis - Pain - Fatigue - Sleep quality.

\section{Introduction}

PAIN, fatigue and sleep disturbance are common constitutional manifestations of Rheumatoid Arthritis (RA); its prevalence is approximately 50$70 \%$ in patients with RA who are receiving medical treatment $[1,2]$.

Reduced working capacity, chronic diseaserelated inflammation, disease activity and joints stiffness, medications relate $3 \mathrm{~d}$ factors, and psychological stress related to chronic illness have

Correspondence to: Dr. Mervat Essam Behiry, E-Mail: Mervat.saad@kasralainy.edu.eg confound effect on general symptoms as pain and fatigue in RA subjects [3] which in turn give the risk of sleep disturbances and decrease work productivity leading to poor quality of life, long term morbidities and increased functional burden [4]

Beside the common causes of pain in general population, a constellation of many factors (neuropathic and musculoskeletal) is associated with RA. Neuropathic pain with continuous nociceptors stimulation or non-neuropathic type can be contributed to tissue injury and release of cytokines as interleukin 1 and 6 and tumor necrosis factor $\alpha$ (TNF- $\alpha$ ) that trigger anxiously the spinal cord excitability and enhance the pain pathway [5]

Many questionnaires have been emerged to assess sleep quality and fatigue [6] such as patient-reported measures include the Pittsburgh Sleep Quality Index (PSQI), Epworth Sleepiness Scale (ESS) [9] and the Athens Insomnia Scale (AIS) [10]

Accordingly, the aim of this work to study fatigue, pain and sleep problems in RA patients and their relation with the disease activity and patients characteristics.

\section{Patients and Methods}

A cross-sectional study included 84 RA Egyptian patients fulfilling the 2010 American College of Rheumatology (ACR)/European League Against Rheumatism classification criteria for RA [9] and aged $\geq 18$ years were recruited consecutively from Rheumatology Outpatient Clinic, Internal Medicine Department at Cairo University Hospital during the study period (June 2017 to Dec. 2017), while patients who were pregnant, with severe hepatic and renal dysfunction and whose disease duration less than 6 months, those with past history of major depression or psychiatric illness, drug abuse, concurrent presence of fibromyalgia were excluded. 
Informed consent from each participant was obtained. The study protocol was treated according to Helsinki declarations of biomedical ethics and approved by Local Ethical Committee.

All enrolled patients were subjected to full history taking and clinical examination including pain, sleep and fatigue assessment and disease activity by DAS score.

Laboratory workup: The performed laboratory tests were hemoglobin, creatinine, Erythrocyte Sedimentation Rate (ESR), Rheumatoid Factor (RF) and C-Reactive Protein (CRP).

\section{Data collection tools:}

A pre-tested anonymous structured interview questionnaire was used to collect the data. Most of the questions were close-ended and were precoded before data collection to facilitate data entry and analysis. The questionnaire included questions about the following data:

1-Sociodemographic characteristics: Age, education, occupation, and residence.

2- Pain intensity assessment: By using pain Visual Analog Scale (VAS) which is a simple measurement instrument that tries to measure a characteristic that is across a continuum of values and presented in a number of ways, including scales with a middle point, graduations or numbers (numerical rating scales). Using a ruler, the score is determined by measuring the distance $(\mathrm{mm})$ on the $10-\mathrm{cm}$ line between the "no pain" anchor and the patient's mark, providing a range of scores from 0-100. A higher score indicates greater pain intensity [10]

3- Fatigue rating:Fatigue Severity Scale (FSS) is a method of evaluating the impact of fatigue. FSS questionnaire addresses fatigue's effects on daily functioning, querying its relationship to motivation, physical activity, work, family, and social life, and Respondents used a scale ranging from 1 ("completely disagree") to 7 ("completely agree") to indicate their agreement to rate the ease with which they were fatigued and the degree to which the symptom poses a problem for them [11]

4- Sleep quality evaluation: The Pittsburgh Sleep Quality Index (PSQI) is a self-rated questionnaire, which assesses sleep quality and disturbances over a 1-month time interval. It is composed of 7 clinically-derived component scores, each weighted equally from $0-3$. The 7 component scores are added to obtain a global score ranging from $0-21$, with higher scores indicating worse sleep quality [12].
5-Disease Activity Score 28 (DAS 28): The DAS28 is a system developed and validated by the EULAR (European League against Rheumatism) to measure the disease activity and the progress of RA. It depends on number of swollen and tender joints, measured Erythrocyte Sedimentation Rate (ESR) and finally subjective assessment of disease activity by the patient during the preceding 7 days on a scale between 0 and 100 ("0": No activity, "100": Highest activity possible) DAS28 values range from 2.0 to 10.0 while higher values mean a higher disease activity. A DAS $28<3.2$ is interpreted as inactive disease [13].

\section{Statistical methodology:}

After data collection, all questionnaires were reviewed for completeness and logical consistency. Pre-coded data were entered into Microsoft Office Excel for Windows, 2013. Data were then double checked and transferred to Statistical Package for the Social Sciences, Version 24 (SPSS-V24). Graphs were generated using Microsoft Office Excel. All statistical analyses were performed using two-tailed tests and an alpha error of 0.05. A $p$ value $\leq 0.05$ was considered statistically significant. Simple descriptive statistics (arithmetic mean and standard deviation) were used to summarize the normally distributed quantitative data, and frequencies were used to summarize the qualitative data. Pearson's test was used for correlations. Independent samples $t$-tests, one-way ANOVA, and posthoc tests were used to compare normally distributed quantitative data, while Mann-Whitney and $\mathrm{Kr}$ uskal-Wallis tests were used to compare nonnormally distributed quantitative data.

\section{Results}

Eighty four RA patients were included in the current study. The mean (SD) age was 45(8) years with range of (20-67 years). Most of them were female 67 (79.8\%). RA patients had poor sleep quality and higher score of pain and fatigue scales. The demographic, clinical and laboratory data of the studied subjects are summarized in (Table 1).

Most of the patients (66.7\%) had moderate disease activity assessed by DAS28 score.

\section{All patients were manifesting with joint affection:}

The current data revealed a significant positive correlation between PSQI score, VAS pain and FSS scales versus age, ESR measure, duration of the disease as well as disease activity by DAS28 as shown in (Table 2). 
Table (1): Demographics, clinical and laboratory characteristics of the studied patients.

\begin{tabular}{|c|c|}
\hline Variables & $\mathrm{N}=84$ \\
\hline Age in years (mean $\pm \mathrm{SD})$ & $45 \pm 8$ \\
\hline Female $(\mathrm{N}, \%)$ & $67(79.8 \%)$ \\
\hline Male $(\mathrm{N}, \%)$ & $17(20.2 \%)$ \\
\hline \multicolumn{2}{|l|}{ Education $(N, \%)$ : } \\
\hline Illiterate & $11(13.1 \%)$ \\
\hline Secondary & $16(19.0 \%)$ \\
\hline Institute & $43(51.2 \%)$ \\
\hline University & $14(16.7 \%)$ \\
\hline \multicolumn{2}{|l|}{ Occupation $(N, \%)$ : } \\
\hline Working for cash & $33(39.3 \%)$ \\
\hline Not working & $51(60.7 \%)$ \\
\hline \multicolumn{2}{|l|}{ Marital status $(N, \%)$ : } \\
\hline Married & $67(79.8 \%)$ \\
\hline Single & $17(20.2 \%)$ \\
\hline \multicolumn{2}{|l|}{ Residence $(N, \%)$ : } \\
\hline Urban & $32(38.1 \%)$ \\
\hline Rural & $52(61.9 \%)$ \\
\hline Disease duration in years (mean $\pm \mathrm{SD}$ ) & $6.5 \pm 2.5$ \\
\hline \multicolumn{2}{|l|}{ Clinical characteristic $(N, \%)$ : } \\
\hline Arthritis/arthralgia & $84(100 \%)$ \\
\hline Renal disease & $10(11.9 \%)$ \\
\hline Central nervous disease & $4 \quad(4.8 \%)$ \\
\hline Cardiovascular disease & $8 \quad(9.5 \%)$ \\
\hline \multicolumn{2}{|l|}{ Medications: } \\
\hline - Methotrexate & $78(92.8 \%)$ \\
\hline - Antimalarial & $75(89.2 \%)$ \\
\hline - Steroids & $40(47.6 \%)$ \\
\hline - Leflunamide & $25(29.7 \%)$ \\
\hline - TNF blockers & $15(17.8 \%)$ \\
\hline \multicolumn{2}{|l|}{ Laboratory characteristics (mean $\pm S D)$ : } \\
\hline Hemoglobin \% (gm/dl) & $10.8 \pm 2.6$ \\
\hline Creatinine $(\mathrm{mg} / \mathrm{dl})$ & $0.8 \pm 0.03$ \\
\hline $\operatorname{ESR}(\mathrm{mm} / \mathrm{hr})$ & $60 \pm 23$ \\
\hline Positive CRP $(\mathrm{N}, \%)$ & $58(69 \%)$ \\
\hline Positive RF $(\mathrm{N}, \%)$ & $63(75 \%)$ \\
\hline DAS28 score (mean $\pm S D)$ : & $4.2 \pm 1.3$ \\
\hline$\leq 3.2(\mathrm{~N}, \%)$ & $22(26.2 \%)$ \\
\hline$>3.2$ to $\leq 5.1(\mathrm{~N}, \%)$ & $56(66.7 \%)$ \\
\hline$>5.1(\mathrm{~N}, \%)$ & $6 \quad(7.1 \%)$ \\
\hline VAS pain score $(\mathrm{cm})($ mean $\pm \mathrm{SD})$ & $7 \pm 2.39$ \\
\hline FSS score $($ mean $\pm \mathrm{SD})$ & $5.13 \pm 1.75$ \\
\hline PSQI score (mean $\pm \mathrm{SD})$ & $12.6 \pm 3.5$ \\
\hline
\end{tabular}

ESR : Erythrocyte Sedimentation Rate.

CRP : C Reactive Protein.

RF : Rheumatoid Factor.

DAS : Disease Activity Score.

PSQI : Pittsburgh Sleep Quality Index.

FSS : Fatigue Severity Scale.

VAS : Visual Analogue Scale.
Table (2): Correlation of PSQI, FSS and VAS with different variables.

\begin{tabular}{lccccccc}
\hline & \multicolumn{2}{c}{ PSQI score } & \multicolumn{2}{c}{ FSS score } & \multicolumn{2}{c}{ VAS score } \\
Variables & $\begin{array}{r}r \text { - } \\
\text { value }\end{array}$ & $\begin{array}{c}p \text { - } \\
\text { value }\end{array}$ & $\begin{array}{c}r \text { - } \\
\text { value }\end{array}$ & $\begin{array}{c}p \text { - } \\
\text { value }\end{array}$ & $\begin{array}{c}r \text { - } \\
\text { value }\end{array}$ & $\begin{array}{c}p- \\
\text { value }\end{array}$ \\
\hline Age & 0.42 & 0.02 & 0.43 & 0.03 & 0.42 & 0.02 \\
Duration of the disease & 0.56 & 0.04 & 0.52 & 0.02 & 0.56 & 0.04 \\
ESR & 0.64 & 0.002 & 0.6 & 0.001 & 0.64 & 0.002 \\
Hemoglobin\% & -0.17 & 0.3 & -0.54 & 0.02 & -0.17 & 0.3 \\
DAS 28 & 0.75 & 0.02 & 0.85 & 0.001 & 0.74 & 0.03 \\
FSS & 0.4 & 0.03 & & & 0.73 & 0.03 \\
VAS & 0.23 & 0.01 & & & & \\
\hline
\end{tabular}

PSQI : Pittsburgh Sleep Quality Index.

FSS : Fatigue Severity Scale.

VAS : Visual Analogue Scale.

ESR : Erythrocyte Sedimentation Rate.

DAS : Disease Activity Score.

Patients with positive CRP had significantly higher scores of PSQI, FSS \& VAS (13.6 \pm 3.5 , $5.1 \pm 0.75 \& 7 \pm 2.39$ respectively) than those with negative CRP $(10.4 \pm 2.7,4.5 \pm 0.6 \& 5.7 \pm 1.35$ respectively) with $p$-value $>0.05$. However, patients with positive RF did not differ in PSQI, VAS and FSS scales $(10.6 \pm 4.5,4.1 \pm 0.65 \& 5.5 \pm 1.5$ respectively) than those with negative RF (10.4 \pm 2.7 , $3.8 \pm 0.4 \& 5 \pm 1.3$ respectively) with $p$-value $>0.05$.

None of fatigue scale, pain score and sleep scores differed as regard sex, type of medications, marital, educational or occupational status and residency.

\section{Discussion}

The study revealed that Egyptian RA patients are characterized by higher score of pain and fatigue with poor sleep quality. Sleep disturbances, fatigue and pain feature many autoimmune diseases such as ankylosing spondylitis [14], systemic Lupus erythematosus [15], which are related to chronic inflammation, and disease activity.

RA is a chronic autoimmune disease affecting mainly joints and reduced sleep quality and chronic fatigue are common among patients of RA [16] which exerts a significant impact on quality of life and detrimental effects on physical functioning, socio-occupational health and patients' well-being [17].

Presently, the study found that the PSQI was high among the RA patients and this is consistent with many studies that demonstrated poor sleep quality in RA [18-20]. Similarly, other studies revealed RA patients had poor sleep score compared to controls $[21,22]$. 
Pain and fatigue are interrelated in RA and the severity of pain determines the grade of fatigue. In the current work, patients had worse perception of pain and fatigue (high VAS score and FSS), this observations is in accord with previous researches that reported that fatigue and pain commonly occur in RA [23,24].

Most of the enrolled patients had active disease, in attempt to correlate disease activity and sleep, pain and fatigue scores; the study found that there was significant positive correlation between PSQI, FSS, and VAS pain scores and DAS28, this observation corroborates the results of many researches that reported sleep scores significantly correlated with the rheumatoid arthritis activity [12-25]. In addition Paulina et al., had noted that hospitalized RA patients suffered from poor sleep quality assessed by PSQI and fatigue using Functional Assessment of Chronic Illness Therapy-Fatigue (FACIT-F) [17] . PSQI was significantly related to FSS and VAS score indicating the interplay of pain and fatigue in sleep abnormality among RA patients [26]. On the contrary, past studies concluded that sleep disorders not related to RA activity or disease status $[27,28]$.

Also, the current result demonstrated that disease duration is significantly correlated with PSQI, FSS and VAS scores. This is for the reason that the prolonged duration of the disease may be associated with deformities, physical disabilities and psychological depression that potentially impact on fatigue and sleep quality, this is consistent with results obtained from previous study [17].

The present study showed that the presence of CRP is related to worse scores of sleep, pain, and fatigue while positive rheumatoid factor did not differ. In agreement with Goes et al., who found that depression was only independent factor for PSQI score and no association between Sleep disturbance and presence of RF or Anti-CCP [29] but this is not matching with a recent study which was conducted on Egyptian RA patients and concluded that sleep scores were related to the presence of RF, and poor sleep quality can be related to pain, disease activity and physical disability [26]

Herein, different types of drugs did not affect the sleep and fatigue scores and this is in agreement with reports that suggested no association between use of medications and sleep quality $[4,25]$. However, better sleep scores were noticed in patients who received methotrexate [26], and use of biological drugs such as abatacept [30] or infliximab [28]
The current study observed a positive correlation of high scores of PSQI, FSS and VAS and age of patients. Contradictory to this result, many researches concluded no correlation between sleep disturbance and age among RA patients $[17,26,31]$

In this study, sleep, pain and fatigue scores were not comparable regarding sex, residency, marital, occupational or educational status.

It is worthy to mention the shortcomings of this work, first the small sample size; the results of this study will need confirmation in a larger patient population. Second the descriptive nature of the study.

\section{Conclusion:}

The current investigation has identified that Egyptian RA patients have a poor sleep quality, which is significantly correlated to the disease activity, pain and fatigue scales.

\section{Acknowledgment:}

I would like to thank all the participants in this work.

Disclosure: None.

\section{References}

1- LUYSTER F.S., CHASENS E.R., WASKO M.C. and DUNBAR-JACOB J.: Sleep quality and functional disability in patients with rheumatoid arthritis. J. Clin. Sleep Med., 7 (1): 49-55, 2011.

2- DREWES A.M., NIELSEN K.D., HANSEN B., TAAGHOLT S.J., BJERREGARD K. and SVENDSEN L.: A longitudinal study of clinical symptoms and sleep parameters in rheumatoid arthritis. Rheumatology (Oxford), 39 (11): 1287-9, 2000.

3- IRWIN M.R., OLMSTEAD R., CARRILLO C., SADEGHI N., FITZGERALD J.D., RANGANATH V.K., et al.: Sleep loss exacerbates fatigue, depression, and pain in rheumatoid arthritis. Sleep, 35: 537-43, 2012.

4- NICASSIO P.M., ORMSETH S.R., CUSTODIO M.K., IRWIN M.R., OLMSTEAD R. and WEISMAN M.H.: A multidimensional model of fatigue in patients with rheumatoid arthritis. J. Rheumatol., 39: 1807-13, 2012.

5- DREWES A.M.: Pain and sleep disturbances with special reference to fibromyalgia and rheumatoid arthritis. Rheumatology, 38: 1035-8, 1999.

6- WELLS G.A., LI T., KIRWAN J.R., PETERSON J., ALETAHA D., BOERS M., et al.: Assessing quality of sleep in patients with rheumatoid arthritis. J. Rheumatol., 36: 2077-86, 2009.

7- OMACHI T.A.: Measuring sleep in rheumatologic diseases: Epworth Sleepiness Scale (ESS), Functional Outcome of Sleep Questionnaire (FOSQ), Insomnia Severity Index (ISI), and Pittsburgh Sleep Quality Index (PSQI). Arthritis Care Res. (Hoboken), 63 (Suppl 11): S287-S96, 2011. 
8- SOLDATOS C.R., DIKEOS D.G. and PAPARRIGOPOULOS T.J.: Athens insomnia scale: Validation of an instrument based on ICD-10 criteria. J. Psychosom. Res., 48 555-60, 2000.

9- ALETAHA D., NEOGI T., SILMAN A.J., FUNOVITS J., FELSON D.T., BINGHAM 3 rd C.O., et al.: 2010 rheumatoid arthritis classification criteria: An American College of Rheumatology/European League Against Rheumatism collaborative initiative. Arthritis. Rheum., 62 (9): 2569-81, 2010.

10-HAWKER G., MIAN S., KENDZERSKA T. and FRENCH M.: Measures of Adult Pain. Arthritis Care and Research, 68 (11): 240-52, 2011

11- LEE H., JEONG S., LIM M., CHO B., MA Y., KO E., et al.: Reliability and Validity of the Fatigue Severity Scale among University Student in South Korea. Korean Journal of Biological Psychiatry, 20: 6-11, 2013.

12- BUYSSE D.J., REYNOLDS 3 rd C.F., MONK T.H., BERMAN S.R. and KUPFER D.J.: The Pittsburgh sleep quality index: A new instrument for psychiatric practice and research. Psychiatry Res., 28 (2): 193-213, 1989.

13- PREVOO M.L., VAN 'T HOF M.A., KUPER H.H., VAN LEEUWEN M.A., VAN De PUTTE L.B. and VAN RIEL P.L.: Modified disease activity scores that include twentyeight-joint counts. Development and validation in a prospective longitudinal study of patients with rheumatoid arthritis. Arthritis Rheum., 38 (1): 44-8, 1995.

14- ABDULAZIEZ O. and ASAAD T.: Sleep problems in ankylosing spondylitis: Polysomnographic pattern and disease related variables. Egypt Rheumat., 34 (2): 59-65, 2012.

15- PALAGINI L., TANI C., MAURI M., CARLI L., VAGNANI S., BOMBARDIERI S., GEMIGNANI A. and MOSCA M.: Sleep disorders and systemic lupus erythematosus Lupus., 23 (2): 115-23. Doi: 10.1177/ $0961203313518623,2014$.

16- LUYSTER F.S., CHASENS E.R., WASKO M.C. and DUNBAR-JACOB J.: Sleep quality and functional disability in patients with rheumatoid arthritis. J. Clin. Sleep Med., 7 (1): 49-55, 2011.

17- PAULINA S., GRA ŻYNA B. and KATARZYNA K.: Fatigue and sleep quality in rheumatoid arthritis patients during hospital admission. Reumatologia, 55, 2: 65-72 Doi: https://doi.org/10.5114/reum.2017.67600, 2017.

18- LEE Y.C., LU B., EDWARDS R.R., WASAN A.D., NASSIKAS N.J., CLAUW D.J., et al.: The role of sleep problems in central pain processing in rheumatoid arthritis. Arthritis Rheum., 65 (1): 59-68, 2013.

19- SARIYILDIZ M.A., BATMAZ I., BOZKURT M., BEZ Y., CETINCAKMAK G.M., YAZMALAR L., et al.: Sleep quality in rheumatoid arthritis: Relationship between the disease severity, depression, functional status and the quality of life. J. Clin. Med. Res., 6: 44-52, 2014.

20- SON C.N., CHOI G., LEE S.Y., LEE J.M., LEE T.H., JEONG H.J., et al.: Sleep quality in rheumatoid arthritis, and its association with disease activity in a Korean population. Korean J. Intern. Med., 30 (3): 384-90, 2015.

21- ABBASI M., YAZDI Z. and REZAIE N.: Sleep disturbances in patients with rheumatoid arthritis. Niger. J. Med., 22 (3): 181-6, 2013

22- TAYLOR-GJEVRE R.M., GJEVRE J.A., NAIR B., SKOMRO R. and LIM H.J.: Components of sleep quality and sleep fragmentation in rheumatoid arthritis and osteoarthritis. Musculoskeletal Care, 9 (3): 152-9, 2011.

23- GOSSEC L., STEINBERG G., ROUANET S. and COMBE B.: Fatigue in rheumatoid arthritis: Quantitative findings on the efficacy of tocilizumab and on factors associated with fatigue. The French multicentre prospective PEPS Study. Clin. Exp. Rheumatol., 33: 664-70, 2015.

24- STEENBERGEN H.W., TSONAKA R., HUIZINGA T.W., et al.: Fatigue in rheumatoid arthritis; a persistent problem: A large longitudinal study. R.M.D. Open, 4: 1-9, 2015.

25- WESTHOVENS R., VAN DER ELST K., MATTHYS A., TRAN M. and GILLOTEAU I.: Sleep problem in patients with RA. J. Rheumatol., 41: 31-40, 2014.

26- MERVAT I. and MOHAMED N.: Can rheumatoid arthritis affect sleep in Egyptian patients? Egyptian Rheumat, 40 11-6, 2018.

27- FRAGIADAKI K., TEKTONIDOU M.G., KONSTA M. CHROUSOS G.P. and SFIKAKIS P.P.: Sleep disturbances and interleukin 6 receptor inhibition in rheumatoid arthritis. J. Rheumatol., 39 (1): 60-2, 2012.

28- ZAMARRÓN C., MACEIRAS F., MERA A. and GÓMEZ-REINO J.J.: Effect of the first infliximab infusion on sleep and alertness in patients with active rheumatoid arthritis. Ann. Rheum. Dis., 63: 88-90, 2004.

29- GOES A.C.J., REIS L.A.B., SILVA M.B.G., KAHLOW B.S. and SKARE T.L.: Rheumatoid arthritis and sleep quality. Rev. Bras. Reumatol. Engl. Ed. Jul.-Aug., 57 (4): 294-8. Doi: 10.1016/j.rbre.2016.07.011, 2017.

30- WELLS G., LI T. and TUGWELL P.: Investigation into the impact of abatacept on sleep quality in patients with rheumatoid arthritis, and the validity of the MOS-Sleep Questionnaire Sleep Disturbance Scale. Ann. Rheum. Dis., 69: 1768-73, 2010.

31- AUSTAD C., KVIEN T.K., OLSEN I.C. and UHLIG T. Sleep disturbance in patients withrheumatoid arthritis is related to fatigue, disease activity, and other patientreported outcomes. Scand. J. Rheumatol., 46: 95-103, 2017. 


\section{نومية النوم والتعب \\ للى مرضى إلتهاب المفاصل الروماتويدى الهصريبن}

تم ربط الآلم والتعب وإضطرابات النوم بإنذفاض جودة الحياة وإنخفاض معدل البقاء بين المرضى الذين يعانون من إلتهاب المفاصل

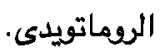

وتهدف هذه الدراسة إلى تقييم إضطرابات النوم والآلم وكذالك آعراض التعب بين مرضى إلتهاب المفاصل الروماتويدى وعلاقة تلك الآعراض بالنشاط المرضى وغيرها من البيانات المميزة للمريض.

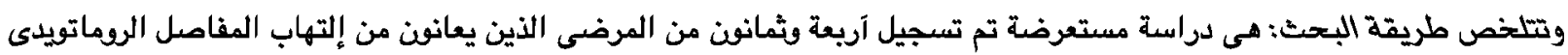

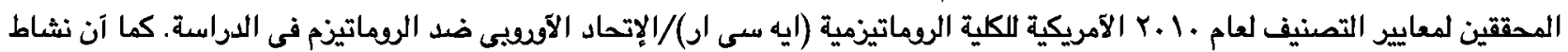

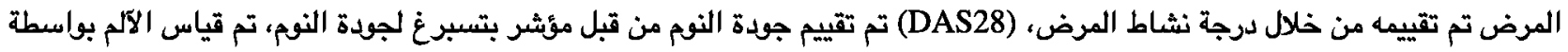

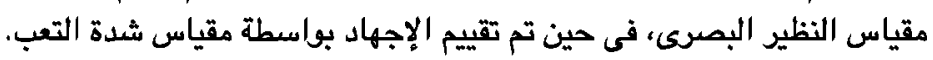

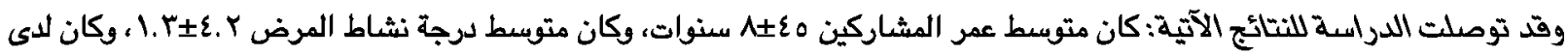

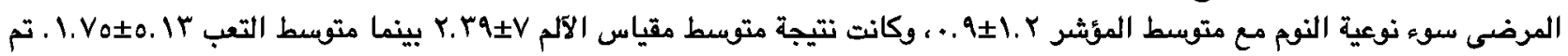

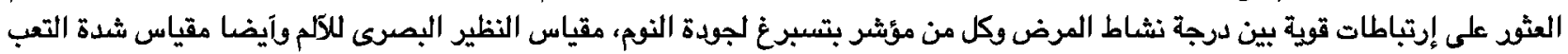

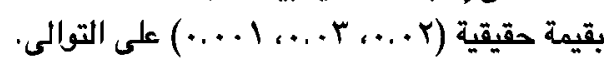
الخلاصة: لوحظ إضطرابات النوم والتعب عادة فى مرضى المفاصل الروماتويدى بسبب تفاعل الآلم ونشاط المرض. 